\title{
Choice Architecture and Design with Intent
}

\author{
Dan Lockton \\ Cleaner Electronics Research Group, Brunel Design, \\ Brunel University, Uxbridge, Middlesex UB8 3PH \\ Daniel.Lockton@brunel.ac.uk
}

\author{
David Harrison \\ Cleaner Electronics Research Group, Brunel Design, \\ Brunel University, Uxbridge, Middlesex UB8 3PH \\ David.Harrison@brunel.ac.uk
}

\author{
Neville A. Stanton \\ School of Civil Engineering \& the Environment, \\ University of Southampton, \\ Southampton, Hampshire SO17 1BJ \\ N.Stanton@soton.ac.uk
}

\begin{abstract}
Motivation - Choice architecture (Thaler \& Sunstein, 2008) is a phrase of the moment among politicians and economists seeking to influence public behaviour, but the relevance of the concept to designers has received little attention. This paper places choice architecture within the context of Design with Intent-design intended to influence user behaviour. Research approach - The concepts are introduced and choice architecture is deconstructed. Findings/Design - Affordances and Simon's behavioural model (1955) help understand choice architecture in more detail. Research limitations/Implications - This is only a very brief, limited foray into what choice architecture is. Originality/Value - User behaviour can be a major determinant of product efficiency: user decisions can contribute significantly to environmental impacts. Understanding the reasons behind them, a range of design techniques can be identified to help users towards more efficient interactions. Take away message - The intended outcome is a useful design method for helping users use things more efficiently.
\end{abstract}

\section{Keywords}

Design methods, user behaviour, choice architecture, sustainability.

\section{INTRODUCTION}

With the publication of Thaler and Sunstein's (2008) bestseller Nudge, the term choice architecture has entered popular public discourse. Politicians (e.g. Osborne, 2008) can now recognise themselves-or journalists can cast them-as choice architects, alongside decision-makers in every field from estate agents to party planners, health authorities to shopping centre developers. Essentially, everyone who is involved in organising how some set of options or choices is presented to other people is necessarily influencing decision-making behaviour, whether intentionally or otherwise.

Design theorists (e.g. Buchanan, 1985; Redstrom, 2006) have noted this previously, of course, as have-explicitly or otherwise-a generation of HCI practitioners deciding which features should be enabled by default, which should be hidden away on an 'Advanced' tab, and so on. Lots of disciplines involve influencing people's behaviour, with varying levels of decision-making involved for the user, from urban planning to advertising, and product and system design is central to this: as Stanton and Baber (1998) note, '[i]n designing products, designers are also designing user activity, which does not occur independently of the product... [C]onsumer behaviour is shaped by products as much as products are shaped by consumer behaviour.'

While intentionally influencing how users behave is not often explicitly part of a design brief, the opportunity certainly exists, and it is possible to identify often isolated examples from a variety of fields where the design of products, systems, services and environments has been used with the intent of influencing users' behaviour. If certain techniques have effects on user behaviour unintentionally, they could also be applied intentionally for social benefit.

\section{BACKGROUND: DESIGN WITH INTENT AND INFLUENCING SUSTAINABLE BEHAVIOUR}

It seems worthwhile to investigate how some of these techniques might fit together into a method for helping designers working in this field. Using the term 'Design with Intent' (Lockton, Harrison, \& Stanton, 2008a) to define this category of design intended to influence or result in certain user behaviour, we are developing a 'toolkit' (Lockton, Harrison, \& Stanton, 2009) for designers working on 'behaviour change' problems, particularly reducing the environmental impact of products in use (Lockton, Harrison, Holley, \& Stanton, 2009; Lockton, Harrison, \& Stanton, 2008b) where, despite technological advances, it is often human behaviour that's the weak link in the behavioural chain. We buy 'energysaving' lights and then leave them on all night, we boil a kettle-full of water even though we only need a mug-full, and we stick with the default setting on the washing machine, afraid of investigating the others. 
Behavioural decisions (or the lack of them) can be responsible for 26-36\% of household energy use (McCalley \& Midden, 2002; Wood \& Newborough, 2003) — this is a big issue, and while governments often favour social marketing campaigns to 'solve' it, in many ways it's worth thinking about this problem as an intersection of HCI and behavioural economics. It's about people interacting with technology: how and why they decide how to use systems in the way they do, and how that interaction might be influenced (if indeed it should). There is little innately special about more environmentally friendly user behaviour: it's often simply about using a system effectively-thus intrinsically related to usability and user decision-making.

Despite differences in design approach between environments, products (hardware / software) and services, many techniques or their analogues recur across the board. It ought to be possible to abstract certain techniques from one field, and apply them in others. From various kinds of persuasive (Fogg, 2003) energy feedback UIs to affordancebased physical techniques such as segmentation (and interface analogues of these), we have so far identified around 50 design patterns or techniques for influencing user behaviour, grouped into six 'lenses' (Architectural, Errorproofing, Visual, Persuasive, Cognitive and Security) representing different worldviews (e.g. the Cognitive lens draws most heavily on a heuristics and biases approach to behaviour (Kahneman, Slovic, \& Tversky, 1982)). The Design with Intent (DwI) method maps the patterns to particular 'target behaviours', so a design team briefed with influencing a particular kind of user behaviour can be presented with a range of relevant design patterns, along with pros/cons, and example implementations, for each.

The method has been developed and refined through a series of workshop sessions (Figure 1) with design students and recent graduates, evolving from a tree structure ('too prescriptive' was one service design consultancy's verdict) through more visual 'idea space' diagrams. At time of writing we are about to release a simplified 'Design with Intent toolkit' online and in print (Lockton et al., 2009), a guide and reference for inspiration in this area. The first application will be as reference material for a major UK student design contest, the Royal Society of Arts' 2009/10 Design Directions competition brief on behaviour change.

\section{Applying the method}

The second stage of the project involves building functional prototypes of concepts suggested by the method in response to a particular home energy use brief (e.g. a kettle where user behaviour is a major determinant of the amount of electricity used) and running comparative user trials to find out which techniques actually have the biggest effects on behaviour in practice (energy use is easy to measure). It might turn out that a networked kettle with a clever 'social proof' interface, comparing your overfilling habits with your friends', is more effective than one which continually asks 'Are you sure?' every time you fill it, but that a simple more prominent cups / mugs scale is better still.

The results of the trials-which techniques work best, in what situations, what decisions users make about their behaviour and why (both technologically and in human factors terms) - will be fed back into the method to refine it further and, we hope, produce a useful tool for designers involved in influencing user behaviour, especially to reduce environmental impact.
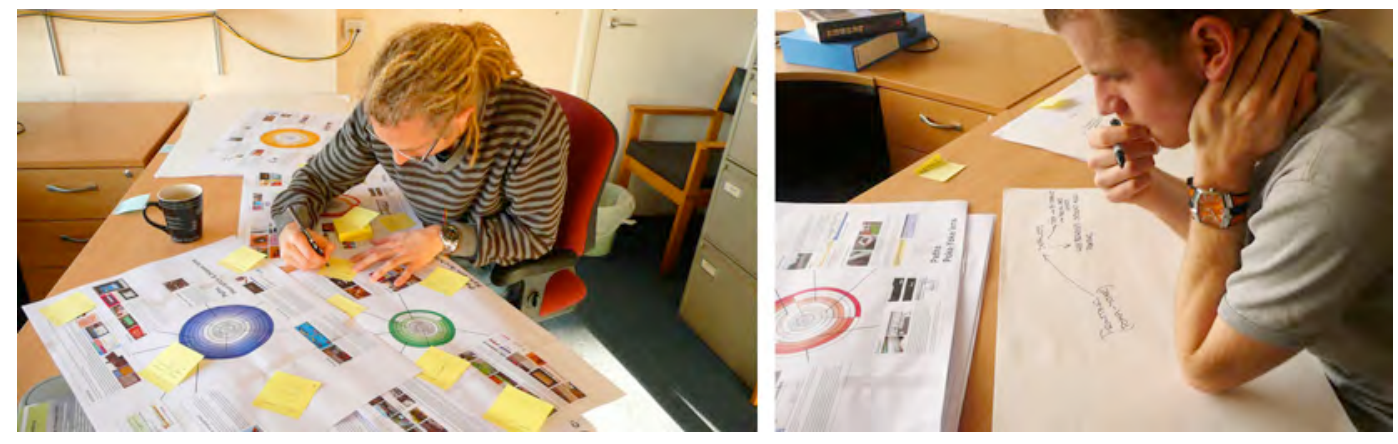

Figure 1. Student workshop sessions

\section{CHOICE ARCHITECTURE}

Returning to the choice architecture idea in the light of 'design with intent' in general, it is interesting to consider the way the concept is framed as being about choices which have been intentionally made available (or not) to the user: this accords with Sunstein and Thaler's (2003) characterisation of the idea as libertarian paternalism, and also signifies applying an essentially economic terminology beyond its traditional boundaries (similarly, perhaps, to thinking about desire lines (Bachelard, 1969; Myhill, 2004) and use-marks (Burns, 2007) as revealed or normative user preferences (Beshears, Choi, Laibson, \& Madrian, 2008)). In the sense of von Foerster's ethical imperative 'Always act in ways that 
increase choice' (Ray, 2005), the role of a choice architect in 'editing' choices for users has the potential to be problematic; similar debates have occurred in the persuasive technology community (e.g. Berdichevsky \& Neuenschwander, 1999) and in design for sustainable behaviour (Pettersen \& Boks, 2008).

\section{Affordances}

Aside from ethical issues, the most obvious observation about choice architecture from a design or HCI perspective is that affordances (Gibson, 1986) or perceived affordances (Norman, 1999) are more likely to be invoked as a concept to design and analyse the options available to users. While there has been some debate (e.g. McGrenere \& Ho, 2000) over the meaning of the term 'affordance' as it is widely applied in interaction design, Gaver's (1991) $2 \times 2$ matrix of perceptible (correctly perceived) affordances, false affordances, hidden affordances and 'correct rejection' (i.e. no affordance present, and none perceived) provides a clear and useful starting point for the classification. Gibson focused mainly on visual perception, but later work, such as Gaver's (1991) discussion of tactile affordances (feeling how sharp a knife is allows us to perceive whether it has the affordance of slicing a tomato) and Stanton and Edworthy's (1998) research on auditory affordances in medical environments, demonstrates a broader range of senses in which perceived affordances can be considered.

Assuming that a system is not designed intentionally to have false or hidden affordances to trick or exclude users, in choice terms, a user can only choose options which he or she perceives have the affordance of being chosen-i.e. correctly perceived affordances.

We might consider that hidden affordances are those which, while they are possible, have been edited out of the choices available to us by the 'choice architect' for some reason. For example, Starbucks' 'short' cappuccino, while theoretically available, is intentionally not listed on the chain's menus (Harford, 2006): the ability to buy a short cappuccino is a hidden affordance, while the abilities to buy the sizes actually on the menu are correctly perceived affordances (assuming the customer has the financial capability to do so: Gibson (1986) makes it clear that an affordance must 'be measured relative to the animal').

What is missing from the simple division into different kinds of affordances is a weighting of some kind for alternative choices, which would determine which of the whole set of correctly perceived affordances are actually acted upon by the user. The processes by which these weightings are assessed by the user and acted upon-and the extent to which the 'cognitive' and 'environmental / ecological' blades in Simon's scissors (Simon, 1990) act—are, of course, what much decision research is about. As Gigerenzer and Fiedler (2004) put it, "it is essential to analyse the adaptive match between cognitive and ecological factors." Choice architecture approached from the designer's domain will probably emphasise the ecological aspects, while approaching it from a psychological angle will favour the cognitive blade.

\section{Simon's behavioural model}

Simon's (1955) categorisation of elements required for a model of rational behaviour is pertinent here. His 'set of behaviour alternatives', assuming they are all possible for a user, corresponds to the set of affordances present. The 'subset of behaviour alternatives that the organism "considers" or "perceives" corresponds to Gaver's perceptible affordances. Simon's other elements—'the possible future states of affairs, or outcomes of choice, 'a "pay-off' function, representing the "value" or "utility" placed by the organism upon each of the possible outcomes of choice', 'information as to which outcomes will actually occur if a particular alternative... is chosen' and 'information as to the probability that a particular outcome will ensue if a particular behaviour alternative is chosen' are all elements making up the weighting of the choices.

In most system design situations, for either usability or safety reasons, we want users to have a high degree of certainty about the outcome and payoff of each choice, so the weighting reduces somewhat in complexity. A product (other than a game) where the user had to work out the probabilities of certain outcomes occurring in response to particular interactions would be difficult and probably unpleasant to use, at least until the user had learned patterns and satisficing heuristics to achieve what was desired (although Csikszentmihalyi's Flow (1991), where a user's skills keep pace with the challenge, may lie behind the enjoyment some users derive from manipulating complex and arcane interfaces).

\section{User decisions and waste}

Yet in many cases, users don't have full information or understanding of what the outcomes or implications of their actions will be beyond the immediate or surface functionality-and this is a major contributor to resource wastage worldwide. For example, one report by a document management company cited by Condon (2006) estimated that FTSE 100 companies typically waste $£ 400$ million per year each on unwanted printing. That waste has an origin, and it’s in millions of individual decision-making errors as users do not fully understand the outcomes of the actions they are taking. The true weighting of the choices users make is either hidden, ignored or poorly understood.

When we ran sessions asking students to use the DwI Method to come up with concepts for improving user efficiency with printing (Lockton et al., 2009) a large proportion of the concepts suggested (Table 1) involved establishing a better link between the choices users made (or didn't make, given the default settings) about print quality, page layout, page scaling, number of copies and so on, and the effects 'down the line' in terms of resources used. 


\begin{tabular}{|c|c|}
\hline Concept & Techniques inspiring it \\
\hline Changed print quality defaults (e.g. draft quality, duplex, greyscale) & Defaults \\
\hline Display showing financial costs of every print job & Self-monitoring; Scarcity \\
\hline $\begin{array}{l}\text { Make print job take exaggeratedly longer the larger it is (intentional } \\
\text { inconvenience leading to creation of new habits) }\end{array}$ & $\begin{array}{l}\text { Operant conditioning; Respondent } \\
\text { conditioning; Lock-in }\end{array}$ \\
\hline $\begin{array}{l}\text { 'Train' user to print more efficiently via an interface on the printer itself } \\
\text { ('Next time, do this...') }\end{array}$ & Kairos; Interface capabilities \\
\hline $\begin{array}{l}\text { Modal pop-up reminders as user is about to print, intelligently suggesting } \\
\text { more efficient ways }\end{array}$ & Self-monitoring; Kairos; Interlock \\
\hline Efficient printing wizard & Tunnelling \\
\hline $\begin{array}{l}\text { Some kind of environmental 'character' to be displayed, to engage users' } \\
\text { emotions and cause them to think about how much they're printing }\end{array}$ & $\begin{array}{l}\text { Affective engagement; Computers as } \\
\text { social actors }\end{array}$ \\
\hline $\begin{array}{l}\text { Video or animation of dramatic environmental events (rainforest, global } \\
\text { temperature, etc) displayed while documents are sent to print, with explicit } \\
\text { linkage made to user printing behaviour }\end{array}$ & $\begin{array}{l}\text { Simulation; Affective engagement; } \\
\text { Self-monitoring }\end{array}$ \\
\hline $\begin{array}{l}\text { Display showing user's/household's/company's contribution to national } \\
\text { statistics on energy/waste }\end{array}$ & Self-monitoring; Social proof \\
\hline $\begin{array}{l}\text { Embarrassing / irritating sound (e.g. siren) to be played when a user prints } \\
\text { inefficiently (calculated) }\end{array}$ & Condition detection; Surveillance \\
\hline Force user to view print preview every time a print job is about to be sent & Interlock; Simulation \\
\hline Make it more difficult / slower process to print documents & Lock-out; Scarcity \\
\hline $\begin{array}{l}\text { Detect accidental or misguided printer settings and ask user 'Are you sure?' } \\
\text { before correcting them }\end{array}$ & Closed loop; Kairos \\
\hline $\begin{array}{l}\text { In office, route shorter / more efficient documents through the print queue } \\
\text { first }\end{array}$ & Segmentation \& spacing \\
\hline In office, position printer where everyone can see who is using it & $\begin{array}{l}\text { Positioning \& prominence; } \\
\text { Surveillance }\end{array}$ \\
\hline $\begin{array}{l}\text { Haptic mouse giving user feedback on the efficiency of his or her printing } \\
\text { as a print job is sent }\end{array}$ & $\begin{array}{l}\text { Feedback through form; Self- } \\
\text { monitoring }\end{array}$ \\
\hline $\begin{array}{l}\text { 'Woodpile' stack of paper is prominent, next to printer, and decreases as } \\
\text { used, maybe weighed }\end{array}$ & $\begin{array}{l}\text { Feedback through form; Self- } \\
\text { monitoring }\end{array}$ \\
\hline
\end{tabular}

Table 1. A selection of concepts generated by students applying the DwI method to help users print more efficiently. The techniques named are some of those suggested by the method

\section{Feedforward}

The concept of feedforward, in an interface design context (Djajadiningrat, Overbeeke, \& Wensveen, 2002) helps clarify this linkage from the user's point of view, and make it more prominent: much like the tooltip that invites us to 'Right-click to display spelling suggestions' when hovering the cursor over the word 'tooltip' (not in Microsoft Word's dictionary, evidently), feedforward effectively presents the user with a simulation, preview or at least a suggestion of what the outcomes of an action could be, to help support decision-making. When combined with feedback on the impacts of what the user has already done, users should be able to help build up their own weightings for the choices in front of them.

\section{Putting this together}

Table 2 shows how some of the concepts we have discussed here fit together. They can be considered subsets of choice architecture which allow a deeper understanding of what the term might mean for designers. It is easy to imagine design 'interventions' occurring in each column, with the level of detail at which this can be done increasing towards the right: while full feedforward and feedback (on the right-hand side) might be the 'best' form of choice architecture for educating the user how to make intelligent decisions about product use, the bluntest form of 'choice architecture' would simply be to remove the affordances (or choices) you don't want the user to have.

It is this reduction in choice which a number of critics of the choice architecture concept fear (e.g. Perks, 2008; Rizzo \& Whitman, 2008): using choice architecture purely to constrain users' behaviour rather than enable or motivate. 


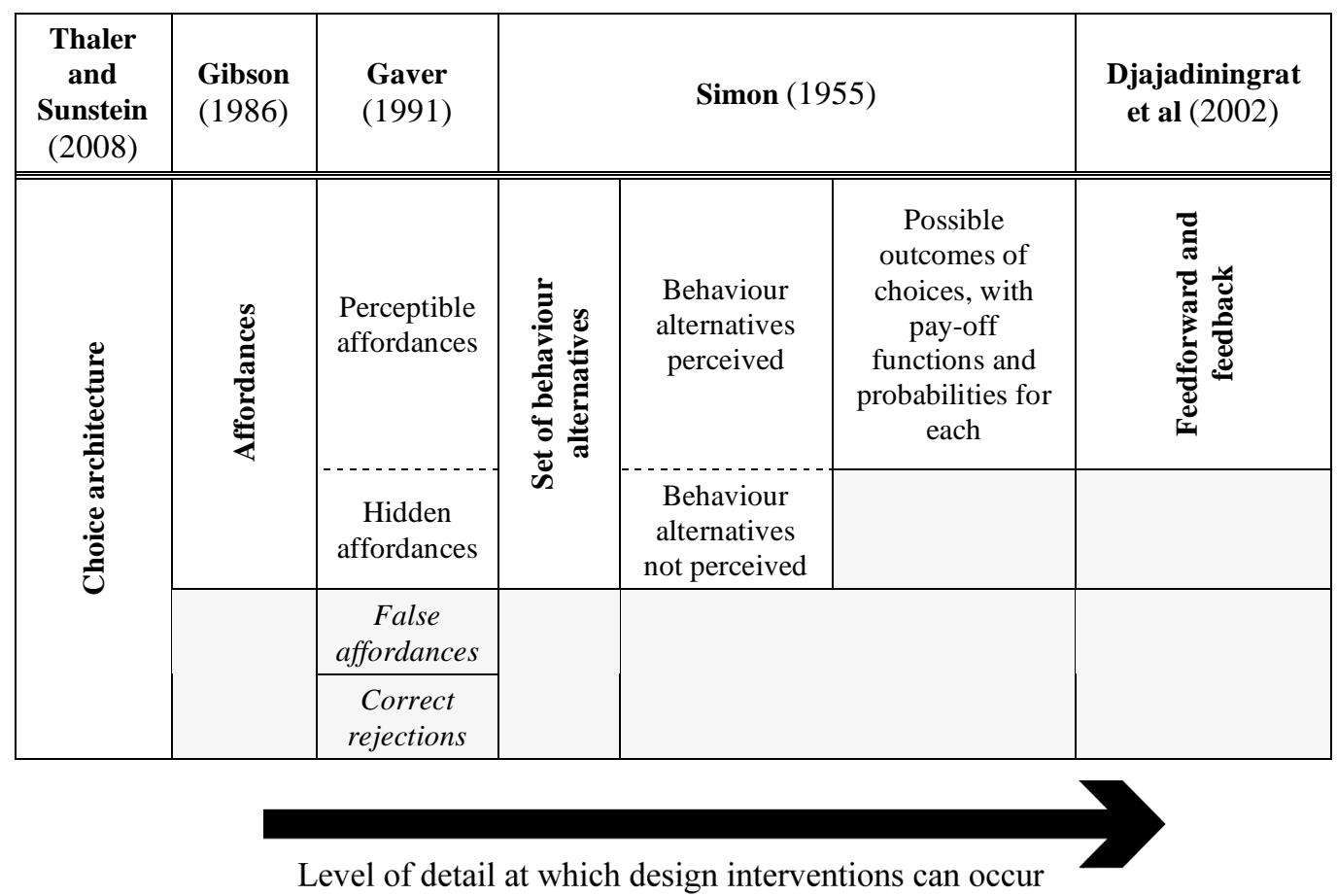

Table 2. Choice architecture subsets and related concepts

\section{CONCLUSION}

This is only a very brief look at choice architecture, alongside an introduction to our Design with Intent research and its potential application in helping people use products more efficiently. A major omission of the choice architecture discussion is a treatment of defaults, which are an important aspect of influencing user behaviour from both behavioural economics (Goldstein, Johnson, Herrmann, \& Heitmann, 2008), and HCI perspectives (Kesan \& Shah, 2006). Nevertheless, we hope that the comparison of affordance classifications and Herbert Simon's work with the choice architecture idea is useful; certainly, it has helped us clarify some different levels of possible design intervention for ourselves.

As our research progresses, we will have more to say about the relative effectiveness of different techniques for understanding and influencing the ways that users make decisions with the products and systems they use, particularly where improvements can help reduce environmental impact.

\section{ACKNOWLEDGMENTS}

This work is funded by the Ormsby Trust, to whom we extend our appreciation.

\section{REFERENCES}

Bachelard, G. (1969). The Poetics of Space. Boston: Beacon Press.

Berdichevsky, D., \& Neuenschwander, E. (1999). Toward an Ethics of Persuasive Technology. Communications of the $A C M, 42(5), 51-58$.

Beshears, J., Choi, J. J., Laibson, D., \& Madrian, B. C. (2008). How are preferences revealed? National Bureau of Economic Research Working Paper Series, 13976.

Buchanan, R. (1985). Declaration by Design: Rhetoric, Argument, and Demonstration in Design Practice. Design Issues, 2(1), 4-22.

Burns, B. (2007, September 20). From Newness to Useness and Back Again: A review of the role of the user in sustainable product maintenance. $\quad$ Retrieved http://extra.shu.ac.uk/productlife/Maintaining\%20Products\%20presentations/Brian\%20Burns.pdf.

Condon, R. (2006, June 26). Paperless office - ages-old myth or valuable way forward? Silicon.com. Retrieved March 17, 2009, from http://www.silicon.com/research/specialreports/governance/0,3800011701,39159888,00.htm.

Csikszentmihalyi, M. (1991). Flow: the Psychology of Optimal Experience. New York: Harper Perennial. 
Djajadiningrat, T., Overbeeke, K., \& Wensveen, S. (2002). But how, Donald, tell us how? On the creation of meaning in interaction design through feedforward and inherent feedback. In Designing Interactive Systems: Proceedings of the 4th conference on Designing interactive systems: processes, practices, methods, and techniques, London (pp. 285-291). New York: ACM Press.

Fogg, B. J. (2003). Persuasive Technology: Using Computers to Change What We think and Do. San Francisco: Morgan Kaufmann.

Gaver, W. W. (1991). Technology Affordances. In Proceedings of the SIGCHI conference on Human factors in computing (p. 79-84). New York: ACM.

Gibson, J. (1986). The Ecological Approach to Visual Perception. Hillsdale: Lawrence Erlbaum Associates.

Gigerenzer, G., \& Fiedler, K. (2004). Minds in Environments: The Potential of an Ecological Approach to Cognition. Berlin: Max Planck Institute for Human Development. Retrieved from http://economics.uchicago.edu/download/MInds_in_Envir.pdf.

Goldstein, D. G., Johnson, E. J., Herrmann, A., \& Heitmann, M. (2008). Nudge Your Customers Toward Better Choices. Harvard Business Review, December.

Harford, T. (2006, January 6). Starbucks Economics: Solving the mystery of the elusive "short" cappuccino. Slate.com. Retrieved March 20, 2009, from http://www.slate.com/id/2133754.

Kahneman, D., Slovic, P., \& Tversky, A. (Eds.). (1982). Judgment under Uncertainty: Heuristics and Biases. Cambridge: Cambridge University Press.

Kesan, J. P., \& Shah, R. C. (2006). Setting Software Defaults: Perspectives from Law, Computer Science and Behavioral Economics. Notre Dame Law Review, 82, 583-634.

Lockton, D., Harrison, D., Holley, T., \& Stanton, N. A. (2009). Influencing Interaction: Development of the Design with Intent Method. In Persuasive Technology: Fourth International Conference, Persuasive 2009, Claremont, California, April 27-29, 2009, Proceedings (p. to appear). New York: ACM Press.

Lockton, D., Harrison, D., \& Stanton, N. (2008a). Design with Intent: Persuasive Technology in a Wider Context. In H. Oinas-Kukkonen, P. Hasle, M. Harjumaa, K. Segerstahl, \& P. Ohrstrom (Eds.), Persuasive Technology: Third International Conference, Persuasive 2008, Oulu, Finland, June 4-6, 2008, Proceedings (p. 274-278). Berlin: Springer.

Lockton, D., Harrison, D., \& Stanton, N. (2008b). Making the user more efficient: Design for sustainable behaviour. International Journal of Sustainable Engineering, 1(1), 3--8.

Lockton, D., Harrison, D., \& Stanton, N. A. (2009). Design for Behaviour Change: The Design with Intent Toolkit v.0.9. Uxbridge: Brunel University Press. Retrieved from http://designwithintent.co.uk.

McCalley, L. T., \& Midden, C. J. H. (2002). Energy conservation through product-integrated feedback: The roles of goal-setting and social orientation. Journal of Economic Psychology, 23, 589--603.

McGrenere, J., \& Ho, W. (2000). Affordances: Clarifying and Evolving a Concept. In Proceedings of Graphics Interface 2000. Montreal.

Myhill, C. (2004). Commercial Success by looking for Desire Lines. In M. Masoodian, S. Jones, \& B. Rogers (Eds.), 6th Asia Pacific Computer-Human Interaction Conference, APCHI 2004, Rotorua: Proceedings. Berlin: Springer.

Norman, D. A. (1999). Affordance, Conventions, and Design. Interactions, 6(3), 38-42.

Osborne, G. (2008, July 14). Nudge, nudge, win, win. Guardian. Retrieved December 31, 2008, from http://www.guardian.co.uk/commentisfree/2008/jul/14/conservatives.economy.

Perks, M. (2008, December 29). 'Nudging': the very antithesis of choice. The Spiked Review of Books. Retrieved from http://www.spiked-online.com/index.php?/site/reviewofbooks_article/6049/.

Pettersen, I. N., \& Boks, C. (2008). The ethics in balancing control and freedom when engineering solutions for sustainable behaviour. International Journal of Sustainable Engineering, 1(4), 287-297.

Ray, W. A. (2005). On being cybernetic. Kybernetes, 34(3/4), 360-364.

Redstrom, J. (2006). Persuasive Design: Fringes and Foundations. In W. IJsselsteijn, Y. de Kort, C. J. H. Midden, B. Eggen, \& E. van den Hoven (Eds.), Proceedings of First International Conference on Persuasive Technology for Human Well-Being, PERSUASIVE 2006 (p. 112-122). Berlin: Springer.

Rizzo, M. J., \& Whitman, D. G. (2008). Little Brother is Watching You: New Paternalism on the Slippery Slopes. New York University School of Law Research Papers, (08-12, 08-15).

Simon, H. A. (1955). A Behavioral Model of Rational Choice. Quarterly Journal of Economics, LXIX, 99-118. 
Lockton $\bullet$ Harrison $\bullet$ Stanton

Design for Sustainable Behaviour

Simon, H. A. (1990). Invariants of Human Behavior. Annual Review of Psychology, 41, 1-19.

Stanton, N. A., \& Baber, C. (1998). Designing for consumers: editorial. Applied Ergonomics, 29(1), 1--3.

Stanton, N. A., \& Edworthy, J. (1998). Auditory affordances in the intensive treatment unit. Applied Ergonomics, 29(5), 389-394.

Sunstein, C. R., \& Thaler, R. H. (2003). Libertarian Paternalism is Not an Oxymoron. University of Chicago Law Review, 70(4), 1159-1202.

Thaler, R. H., \& Sunstein, C. R. (2008). Nudge: Improving Decisions About Health, Wealth, and Happiness. New Haven: Yale University Press.

Wood, G., \& Newborough, M. (2003). Dynamic energy-consumption indicators for domestic appliances: environment, behaviour and design. Energy and Buildings, (35), 821-841. 